\title{
Management of pleural infection in adults: British Thoracic Society pleural disease guideline 2010
}

\author{
Helen E Davies, ${ }^{1,2}$ Robert J 0 Davies, ${ }^{1}$ Christopher W H Davies, ${ }^{2}$ on behalf of the BTS \\ Pleural Disease Guideline Group
}

${ }^{1}$ Oxford Centre for Respiratory Medicine, Churchill Hospital Site, Oxford Radcliffe Hospital, Oxford, UK

${ }^{2}$ Department of Respiratory Medicine, Royal Berkshire Hospital, Reading, UK

\section{Correspondence to Dr Christopher Davies, Department of Respiratory Medicine, Royal Berkshire Hospital, Reading RG1 5AN, UK; chris.davies@royalberkshire. nhs.uk}

Received 12 February 2010 Accepted 4 March 2010

\section{INTRODUCTION}

Pleural infection is a frequent clinical problem with an approximate annual incidence of up to 80000 cases in the UK and USA combined. The associated mortality and morbidity is high; in the UK $20 \%$ of patients with empyema die and approximately $20 \%$ require surgery to recover within 12 months of their infection. ${ }^{1}{ }^{2}$ Prompt evaluation and therapeutic intervention appears to reduce morbidity and mortality as well as healthcare costs. ${ }^{3}$

This article presents the results of a peerreviewed systematic literature review combined with expert opinion of the preferred management of pleural infection in adults for clinicians in the UK. The clinical guidelines generated from this process are presented in figure 1 . The guidelines are aimed predominantly at physicians involved in adult general and respiratory medicine and specifically do not cover in detail the complex areas of tuberculous empyema, paediatric empyema or the surgical management of post-pneumonectomy space infection.

\section{HISTORICAL PERSPECTIVE, PATHOPHYSIOLOGY AND BACTERIOLOGY OF PLEURAL INFECTION}

This section provides background information for reference, interest and to set the management guidelines in context.

\section{Historical perspective}

The Egyptian physician Imhotep initially described pleural infection around $3000 \mathrm{BC}$, although Hippocrates has been more famously credited with its recognition in $500 \mathrm{BC}$. Until the 19th century open thoracic drainage was the recommended treatment for this disorder but carried an associated mortality of up to $70 \%{ }^{45}$ This high mortality was probably due to respiratory failure produced by the large open pneumothorax left by drainage. ${ }^{5}$ This was particularly true of Streptococcus pyogenes infections which produce streptokinase and large alocular effusions free of adhesions. ${ }^{5}$ Closed tube drainage was first described in 1876 but was not widely adopted until the influenza epidemic of 1917-19. An Empyema Commission subsequently produced recommendations that remain the basis for treatment today. They advocated adequate pus drainage with a closed chest tube, avoidance of early open drainage, obliteration of the pleural space and proper nutritional support. These changes reduced mortality to $4.3 \%$ during the later stages of this epidemic.

The introduction of antibiotics both reduced the incidence of empyema and changed its bacteriology. Before antibiotics, $60-70 \%$ of cases were due to Streptococcus pneumoniae which now only accounts for approximately $10 \%$ of culture-positive cases. ${ }^{6}$ The prevalence of Staphylococcus aureus rose and the development of staphylococcal resistance in the 1950s increased complications and mortality. ${ }^{78}$ More recently, the reported prevalence of anaerobic infections ${ }^{7} 910$ and Gram-negative organisms ${ }^{9}{ }^{10}$ has risen. Use of intrapleural fibrinolytic therapy was first suggested in $1949^{11}$ but the impure agents available caused adverse reactions. Most recently, early use of video-assisted thoracoscopic surgical (VATS) techniques has been introduced. ${ }^{12}$

\section{Epidemiology of pleural infection}

The overall incidence of pleural infection is increasing. ${ }^{3}{ }^{13}$ It is well recognised that pleural infection occurs most commonly in the paediatric and elderly populations and recent large-scale cohort studies concur with this finding. Farjah et $a l^{13}$ studied 4424 patients with pleural infection and observed an increase in incidence of $2.8 \%$ per year ( $95 \%$ CI $2.2 \%$ to $3.4 \%$ ). Similarly, in a study population of 11294, between 1995 and 2003 Finley et $a l^{3}$ found an increase in the pleural infection incidence rate ratio (IRR) of 2.2 (95\% CI 1.56 to 3.10$)$ in patients aged $<19$ years and 1.23 (1.14-1.34) in those aged $>19$ years. Age-adjusted incidence rates also increased in their cohort by almost $13 \%$ during the 8 -year period. ${ }^{3}$

Risk factors for pleural infection mirror those for pneumonia although independent considerations for developing empyema include diabetes mellitus, immunosuppression including corticosteroid use, gastro-oesophageal reflux, alcohol misuse and intravenous drug abuse. ${ }^{2} \mathrm{~A}$ history of aspiration or poor oral hygiene is often elicited in anaerobic infection. Iatrogenic pleural infection following pleural interventions and thoracic or oesophageal surgery, trauma or oesophageal perforation account for the majority of remaining cases. Many patients have no apparent risk factors.

\section{Normal pleural fluid physiology}

In health, the volume of pleural fluid in humans is small $(<1 \mathrm{ml})$, forming a film about $10 \mu \mathrm{m}$ thick between the visceral and parietal pleural surfaces. ${ }^{14}$ Pleural fluid contains protein at concentrations similar to the interstitial fluid, a small number of cells (predominantly mesothelial cells, macrophages and lymphocytes) and some large molecular weight proteins such as lactate dehydrogenase (LDH). Compared with serum, pleural fluid in health also contains greater levels of bicarbonate, lower levels of sodium and similar 
Figure 1 Flow diagram describing the management of pleural infection.

\section{Diagnostic algorithm for the management of patients with pleural infection}

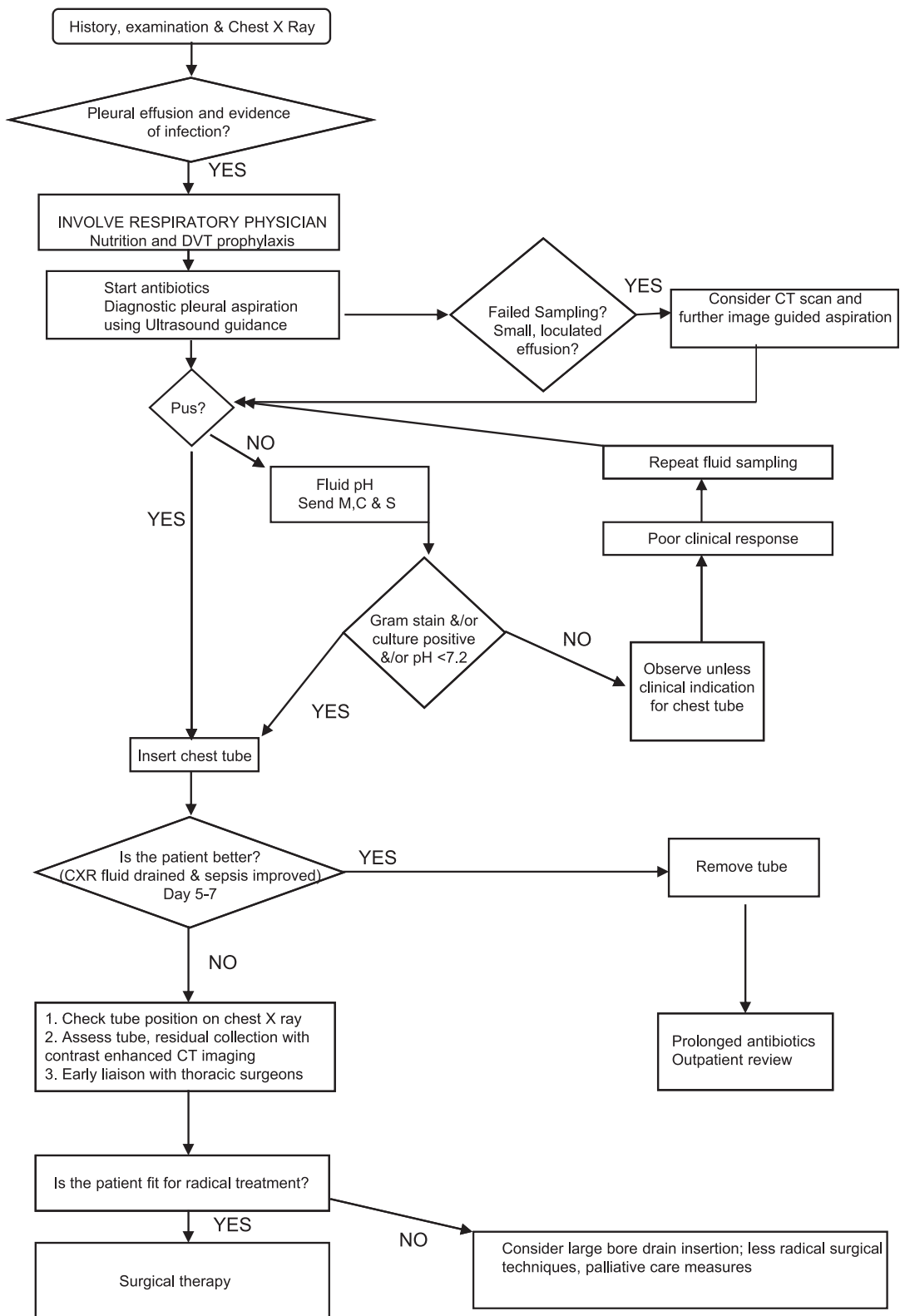

levels of glucose. ${ }^{15}$ The $\mathrm{pH}$ of normal pleural fluid is around 7.6. These parameters change when disease processes affecting the adjacent lung or vascular tissue activate an immune response.

Water and small molecules pass freely between mesothelial cells, while larger particles may be transported by cytoplasmic transport mechanisms or via pleurolymphatic communications. The pleurolymphatic communication is poorly understood, but probably consists of a series of stomata which connect selected areas of the parietal, mediastinal and diaphragmatic pleura, overlying connective tissues and a series of dilated lymphatic channels. ${ }^{14}$

\section{Pathophysiology of pleural infection}

Pneumonia leads to about 110000 emergency hospital admissions each year in the $\mathrm{UK},{ }^{16}$ and the standardised incidence of hospitalisation is increasing (1.98 per 1000 in 2004-5). ${ }^{16} \mathrm{Up}$ to $57 \%$ of patients with pneumonia may develop a pleural effu- $\operatorname{sion}^{17} 18$ but, if appropriate antimicrobial therapy is instigated early, the fluid usually resolves. Most forms of pleural infection represent a progressive process that transforms a 'simple' selfresolving parapneumonic pleural effusion into a 'complicated' multiloculated fibrinopurulent collection associated with clinical and/or biochemical features of sepsis. This may significantly impair respiratory reserve and necessitate surgical drainage. Empyema is the presence of pus within the pleural space.

The development of empyema in association with pneumonia is a progressive process and has been classified into three stages as: (1) a simple exudate, (2) a fibrinopurulent stage and (3) a later organising stage with scar tissue (pleural peel) formation. ${ }^{19}$

In the early exudative stage there is fluid movement into the pleural space due to increased capillary vascular permeability. This is accompanied by the production of proinflammatory cytokines such as interleukin 8 (IL-8) and tumour necrosis factor $\alpha(\mathrm{TNF} \alpha) .{ }^{20} 21$ These produce active changes in the pleural 
mesothelial cells to facilitate fluid entry into the pleural cavity. Initially, the fluid is a free-flowing exudate characterised by a low white cell count, an $\mathrm{LDH}$ level less than half that in the serum, normal $\mathrm{pH}$ and glucose levels and does not contain bacterial organisms. ${ }^{1722-26}$ This stage, when the pleural fluid is a straightforward sterile exudate, is often called a 'simple parapneumonic effusion'. Treatment with antibiotics at this stage is likely to be adequate and most effusions of this type do not require chest tube drainage. ${ }^{17} 2324$

If appropriate treatment is not commenced, a simple parapneumonic effusion may progress to the fibrinopurulent stage with increasing fluid accumulation and bacterial invasion across the damaged endothelium. Bacterial invasion accelerates the immune response, promoting further migration of neutrophils and activation of the coagulation cascade leading to increased procoagulant and depressed fibrinolytic activity. ${ }^{20} 2127$ Increased levels of plasminogen activator inhibitors and decreased tissuetype plasminogen activator (tPA) are seen which favour fibrin deposition and promote formation of septations within the fluid. ${ }^{20}$ Neutrophil phagocytosis and bacterial death fuel the inflammatory process by the release of more bacteria cell wallderived fragments and proteases. ${ }^{21}$ This combination of events leads to increased lactic acid and carbon dioxide production resulting in a fall in pleural fluid $\mathrm{pH}^{28}$ accompanied by increased glucose metabolism and a rise in $\mathrm{LDH}$ levels due to leucocyte death. This leads to the characteristic biochemical features of a fibrinopurulent but not overtly purulent collection that is $\mathrm{pH}$ $<7.20$, glucose $<2.2 \mathrm{mmol} / \mathrm{l}$ and $\mathrm{LDH}>1000 \mathrm{IU} / \mathrm{l}$ consistent with a 'complicated parapneumonic effusion'. ${ }^{17}$ Frank pus is termed 'empyema'.

The final stage is the organising phase in which fibroblasts proliferate. $^{21}$ A solid fibrous pleural peel begins to form which occasionally encases the lung preventing re-expansion, impairing lung function and creating a persistent pleural space with continuing potential for infection.

Pleural infection may also develop without evidence of pneumonia-so-called 'primary empyema'.

\section{Bacteriology of pleural infection}

The microbiological features of pleural infection have altered significantly in modern times, particularly since the introduction of antibiotic therapies in the 1940s.

Pathogens isolated differ between patients with community or hospital-acquired pleural infection (table 1) and iatrogenic aetiology, for example, following thoracic surgery. Acknowledgement of the differing bacteriology should help to guide empirical antibiotic therapy.

\section{Community-acquired pleural infection}

In a recent large trial of 434 patients from over 40 centres in the UK with pleural infection, Gram-positive aerobic organisms were the most frequent organisms identified in communityacquired pleural infection. ${ }^{2}$ Streptococcal species including the $S$ milleri group of organisms and $S$ aureus account for approximately $65 \%$ of cases. ${ }^{2} 9{ }^{29-44}$ Gram-negative organisms-for example, Enterobacteriaceae, Escherichia coli and Haemophilus influenzae-are less commonly cultured and are seen more often in patients with comorbidity. ${ }^{45}$

The frequency of anaerobic isolates is rising and positive pleural fluid cultures in most series report anaerobes in 12-34\%. ${ }^{1} 92933 \quad 35-384042$ However, when identified using different methods such as DNA amplification, anaerobes may be present in up to $76 \%$ of cases $^{7} 313246$ and may be the only pathogen in about 14\% of culture-positive cases. ${ }^{7} 9293638$
Table 1 Bacteriology of community-acquired and hospital-acquired pleural infection ${ }^{2}$

\begin{tabular}{|c|c|}
\hline & Common organisms \\
\hline Community-acquired & $\begin{array}{l}\text { Streptococcus spp. }(\sim 52 \%) \\
\text { S milleri } \\
\text { - } S \text { pneumoniae } \\
\text { S intermedius } \\
\text { Staphylococcus aureus }(11 \%) \\
\text { Gram-negative aerobes }(9 \%) \\
\text { - Enterobacteriaceae } \\
\text { Escherichia coli } \\
\text { Anaerobes (20\%) } \\
\text { - Fusobacterium spp. } \\
\text { - Bacteroides spp. } \\
\text { Peptostreptococcus spp. } \\
\text { - Mixed }\end{array}$ \\
\hline Hospital-acquired & $\begin{array}{l}\text { Staphylococci } \\
\text { Meticillin-resistant } S \text { aureus (MRSA) (25\%) } \\
\text { G } \text { aureus }(10 \%) \\
\text { Gram-negative aerobes (17\%) } \\
\text { E coli } \\
\text { Pseudomonas aeruginosa } \\
\text { - Klebsiella spp. } \\
\text { Anaerobes }(8 \%)\end{array}$ \\
\hline
\end{tabular}

Infections with anaerobes are more likely to have an insidious clinical onset, ${ }^{31}$ with less fever, greater weight loss and are more common following possible aspiration pneumonia and with poor dental hygiene. ${ }^{31}$

\section{Hospital-acquired pleural infection}

In patients with hospital-acquired infection, up to $50 \%$ of patients with positive pleural fluid cultures isolate $S$ aureus. ${ }^{2}$ Meticillin-resistant $S$ aureus (MRSA) may account for up to two-thirds of cases, ${ }^{2}$ although the prevalence of these infections may reduce as greater measures to reduce MRSA infection have been introduced in the last few years. Gram-negative organisms, most commonly E coli, Enterobacter spp. and Pseudomonas spp., are responsible for the majority of the remainder and significantly higher rates of Gram-negative aerobes have been reported in patients who need admission to the intensive care unit. ${ }^{47} 48$

Polymicrobial infection is common with Gram-negative organisms and anaerobes which rarely occur in isolation and which is more frequent in elderly patients and those with comorbid disease. ${ }^{47} 49$

Fungal empyema is rare ( $<1 \%$ of pleural infection). ${ }^{50}$ Candida species are responsible for the majority ${ }^{51}$ and are seen in immunosuppressed individuals. Mortality rates are high (up to $73 \%)^{51}$

The microbiological profile of pleural infection also differs between countries and recognition of this, together with awareness of local antibiotic resistance patterns, is required to optimise treatment. In endemic areas such as Thailand pleural infection is reported in up to $22 \%$ of patients with pulmonary melioidosis (caused by the Gram-negative bacterium Burkholderia pseudomallei). ${ }^{52}$ In cases of pleuropulmonary amoebiasis (Entamoeba histolytica), pleural infection may arise following rupture of a liver collection and transdiaphragmatic spread. ${ }^{53}$

Despite a clinical picture of pleural infection with biochemical confirmation, pleural fluid culture is negative in approximately $40 \%$ of aspirates ${ }^{2} 54$ and, although use of PCR may identify causative organisms more sensitively than conventional culturing methods, PCR is not yet a part of routine clinical practice in most UK centres. $^{2} 55$ 


\section{LITERATURE EVIDENCE AND EXPERT OPINION BEHIND THE GUIDELINE \\ Respiratory specialist care}

- A chest physician or thoracic surgeon should be involved in the care of all patients requiring chest tube drainage for pleural infection. (C)

In view of the substantial mortality associated with pleural infection, the small number of cases seen annually in a single centre and the need for prompt effective therapy, focusing the care of patients in specialist hands is appropriate. Delay to pleural drainage is probably associated with increased morbidity, duration of hospital stay, ${ }^{30} 333656-59$ and may lead to increased mortality. ${ }^{30}$ Misdiagnosis, inappropriate antibiotics and chest tube malpositioning have been cited as important factors contributing to the inadequate management of pleural infection. ${ }^{56}$

An appropriately experienced physician requires the skills to identify patients for surgery and assess thoracic surgical risk, as well as expertise in managing the substantial comorbidities often present. A chest physician best combines these skills as well as having the advantage of an established liaison with thoracic surgical colleagues. In centres with thoracic surgery immediately available, care may be under a physician with a surgical opinion appropriate at any stage in a patient not settling with drainage and antibiotics.

\section{Nutrition \\ - Clinicians should ensure adequate nutrition in patients with pleural infection. (C)}

Poor nutrition was identified during the First World War as an adverse determinant of outcome from pleural empyema but is frequently overlooked. Patients with pleural infection suffer catabolic consequences which may lead to further immunodeficiency and slow recovery. Hypoalbuminaemia is associated with a poor outcome from pleural infection ${ }^{1}$ and clinicians should provide adequate nutritional support and consider supplemental enteral feeding (ie, nasogastric feeding) from the time of diagnosis.

\section{Thrombosis prophylaxis in pleural infection}

- All patients with pleural infection are at high risk for the development of venous thromboembolism and should receive adequate thrombosis prophylaxis with heparin unless contraindicated. (A)

All acutely ill patients with pneumonia and/or pleural infection who have been admitted to hospital should receive prophylactic dose low molecular weight heparin treatment unless contraindicated (eg, bleeding, thrombocytopenia, significant renal impairment, allergy to low molecular weight heparins). ${ }^{60-65}$ In patients with renal impairment, unfractionated heparin should be used (5000 units subcutaneously twice daily). Mechanical prophylaxis and thromboembolic deterrent stockings should be used in those with contraindications to anticoagulant treatment.

\section{Identification: clinical}

- Features of ongoing sepsis and raised $\mathrm{C}$ reactive protein in patients with pneumonia after $\geq 3$ days may indicate progression to pleural infection. (C)

- All patients with suspected pleural infection should have blood cultures for aerobic and anaerobic bacteria performed. (C)

For patients in hospital with community-acquired pneumonia the median time to improvement in heart rate and blood pressure is 2 days, and 3 days for temperature, respiratory rate and oxygen saturation. ${ }^{66}$ A failure to respond to initial management may indicate the presence of a parapneumonic effusion or empyema as a complication of pneumonia.

Indicators of possible progression of pneumonia to pleural infection include ongoing fever and symptoms or signs of sepsis-for example, elevated white cell count and/or inflammatory markers such as $\mathrm{C}$ reactive protein (CRP). CRP is a sensitive marker of progress in pneumonia. ${ }^{67} 68$ Failure of the CRP level to fall by $50 \%$ is associated with an adverse outcome and increased incidence of empyema ${ }^{69}$ and should prompt further evaluation including a repeat chest $x$-ray.

A recent study ${ }^{70}$ used a number of pneumonia severity scores and clinical variables to predict the likelihood of development of complicated parapneumonic effusion and empyema in patients with community-acquired pneumonia. None of the severity scores had any predictive value but seven clinical variables were identified predicting development of pleural infection. The presence of chronic obstructive pulmonary disease was associated with reduced risk of progression to pleural infection, but the following variables were positively predictive: (1) albumin $<30 \mathrm{~g} / \mathrm{l}$; (2) CRP >100 mg/l; (3) platelet count >400×10\%/1; (4) sodium $<130 \mathrm{mmol} / \mathrm{l}$; (5) intravenous drug abuse; and (6) chronic alcohol abuse. Using two or more points as the cut-off, the sensitivity was $87 \%$, specificity $68.3 \%$, positive predictive value $17.7 \%$ and negative predictive value $98.5 \%$. The scoring system requires independent prospective validation.

Blood cultures for bacteria are positive in about 14\% of patients with pleural infection ${ }^{2}$ and, when positive, are often the only source of positive microbiology. Blood cultures should therefore be performed in all patients with suspected pleural infection.

\section{Identification: imaging}

\section{Initial imaging}

Empyema should be suspected in all patients who fail to respond to appropriate antibiotic therapy. A pleural effusion may be obvious on the chest $\mathrm{x}$-ray ${ }^{71}$ and the coexistence of pulmonary infiltrates and fluid should alert the clinician to the possibility of a parapneumonic collection. Lateral chest x-rays may confirm pleural fluid not suspected on the posteroanterior chest x-ray, ${ }^{17}$ however pleural ultrasonography is widely available and is the preferred investigation. Ultrasound enables determination of the exact location of any fluid collection and guided diagnostic aspiration can be performed if required. ${ }^{71} 72$ Increasingly, thoracic ultrasound is being performed alongside the chest $x$-ray in patients with suspected pleural infection. However, unlike chest radiography, ultrasound is not yet routinely available in outpatient settings and out of hours so, for monitoring/follow-up purposes, the chest $\mathrm{x}$-ray remains the initial imaging investigation of choice.

Pleural sepsis is occasionally caused by oesophageal rupture and this diagnosis should be suspected in patients who develop a pleural effusion soon after significant retching or vomiting. Diagnostic strategies to identify this important problem are oesophageal imaging (eg, a contrast-enhanced swallow assessment) and measurement of pleural fluid amylase levels which are raised as swallowed salivary amylase enters the pleural space through the oesophageal perforation. ${ }^{73} 74$ The detection of an oesophageal leak should prompt immediate referral to a surgeon with expertise in the management of oesophageal rupture.

\section{Further radiological assessment}

\section{Ultrasound}

Pleural ultrasonography may help to identify pleural infection. In a study of 320 cases of pleural effusion, ${ }^{75}$ all echogenic 
effusions were caused by exudates and homogeneous echogenic effusions were due to either empyema or haemorrhage.

Correlation between the presence of loculated pleural fluid and a significantly lower pleural fluid $\mathrm{pH}$ and glucose and a high LDH concentration has been shown, ${ }^{76} 77$ although this has not been corroborated by further studies.

\section{CT scanning}

Contrast-enhanced CT scanning with the scan performed in the tissue phase may be of value in patients when the diagnosis is in doubt or an underlying abnormality is thought either to be associated with the empyema or potentially its cause, such as an oesophageal perforation or bronchogenic carcinoma. CT scanning can help to differentiate pleural empyema from a parenchymal lung abscess and may also help to formulate management decisions about drainage, providing guidance for drain insertion and determination of subsequent tube positioning and success of drainage attempts, and the need for surgical intervention.

Empyemas are usually lenticular in shape and compress the lung parenchyma, while lung abscesses often have an indistinct boundary between the lung parenchyma and collection. ${ }^{78} 79$ The 'split pleura' sign caused by enhancement of both parietal and visceral pleural surfaces (figure 2) and their separation in empyema is characteristic of a pleural collection. Pleural thickening is seen in $86-100 \%$ of empyemas ${ }^{80-82}$ and $56 \%$ of exudative parapneumonic effusions. ${ }^{80}$ Pleural thickness on contrast enhanced CT scans is greater in those with frankly purulent effusions, ${ }^{83}$ whereas the absence of pleural thickening suggests a simple parapneumonic collection. ${ }^{80}$ Where pleural infection has progressed, pleural enhancement may be demonstrated with contrast-enhanced CT scanning ${ }^{82}$ and increased attenuation of extrapleural subcostal fat is often seen. ${ }^{78} 80-82$ These signs are absent in transudative effusions. ${ }^{81}$ Moderate $(<2 \mathrm{~cm})$ mediastinal lymphadenopathy is seen in over one-third of patients with pleural infection. ${ }^{83}$

\section{$M R I$}

$\mathrm{MRI}$ is not routinely indicated and offers no advantage over CT scanning for pleural infection; however, it may be considered in

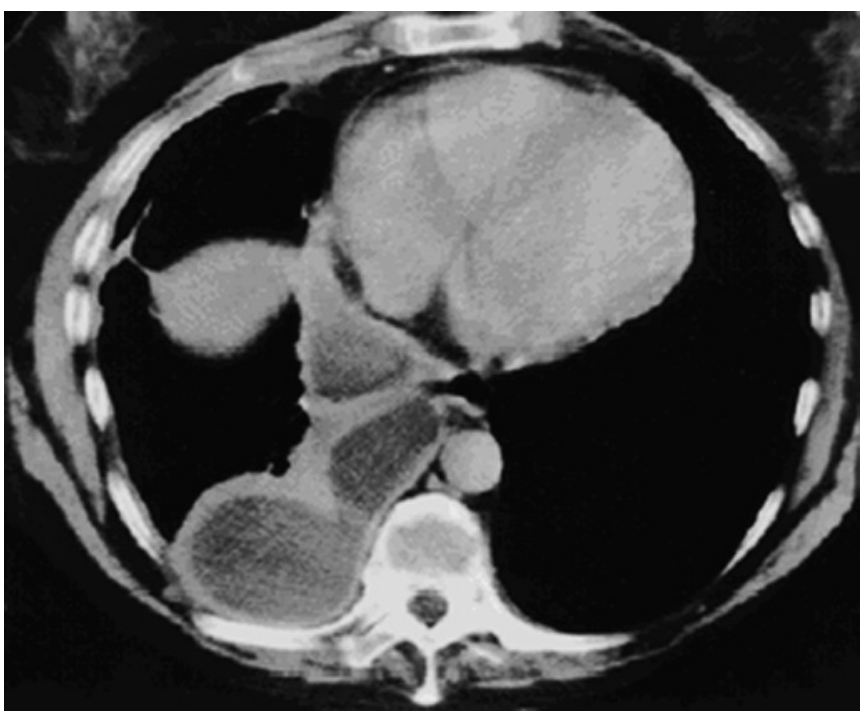

Figure 2 Typical contrast-enhanced CT appearances of pleural empyema. The image shows a multiloculated pleural collection forming separate lenticular pleural opacities. The 'split pleura' sign with enhancing pleural tissue visible on both the visceral and parietal pleural surfaces is shown. specific situations such as allergy to contrast agents or young/ pregnant patients where minimising ionising radiation exposure is a particular priority. MRI can also help to define chest wall involvement with the infection (eg, empyema necessitans or tuberculous empyema).

\section{Identification: pleural fluid aspiration}

- All patients with a pleural effusion in association with sepsis or a pneumonic illness require diagnostic pleural fluid sampling. (C)

If a pleural effusion is identified on the chest x-ray of a patient with possible pleural infection, it is impossible clinically to differentiate the presence of a complicated parapneumonic effusion requiring chest tube drainage from a simple effusion that may resolve with antibiotics alone. There are also no specific data relating to which patients with a parapneumonic effusion can be managed without diagnostic pleural fluid sampling. Sometimes patients seen initially in the community by their general practitioner will have spontaneous resolution of parapneumonic effusions in conjunction with antibiotics without any pleural sampling by the time they present to respiratory specialists. This cohort often present following referral to the outpatient setting with an undiagnosed pleural effusion and repeat imaging confirms radiological improvement.

Although empyemas are more common in men than in women, ${ }^{1} 9335784$ there are no differences in patient age, white cell count, peak temperature, presence of chest pain and extent of radiological infiltrate between patients requiring chest tube drainage for symptom resolution and those who resolve with antibiotics alone. ${ }^{17}$

Pleural fluid characteristics remain the most reliable diagnostic test to guide management, ${ }^{17} 22-247785-87$ and diagnostic pleural fluid sampling is therefore recommended in all patients with a pleural effusion $>10 \mathrm{~mm}$ depth in association with a pneumonic illness or recent chest trauma or surgery and who have features of ongoing sepsis.

Imaging guidance should be used since this minimises risks of organ perforation ${ }^{88}$ and improves the recovery rate of pleural fluid. ${ }^{89}$ Sampling using thoracic ultrasound is simple, safer and will reduce patient discomfort (see guideline on pleural investigation). ${ }^{71} 8990$ Sampling can be performed by sterile procedure using a needle and syringe with local anaesthetic if necessary.

Small effusions (ie, $<10 \mathrm{~mm}$ thickness) will usually resolve with antibiotics alone. ${ }^{1725}$ Observation may be appropriate for these patients, but an increase in the size of the effusion or ongoing sepsis should warrant re-evaluation and diagnostic pleural fluid sampling

Patients in an intensive care unit frequently develop pleural effusions that are not caused by pleural infection. ${ }^{91}$ It is probably safe to observe such patients with hypoalbuminaemia, heart failure or atelectasis who are at low risk of infection while treating the underlying condition. ${ }^{91}$ Pleural fluid should be sampled if there are features of sepsis using ultrasound guidance, particularly in patients receiving positive pressure ventilation.

- Pleural fluid pH should be assessed in all non-purulent effusions when pleural infection is suspected. (B)

- If pleural fluid pH measurement is not available, pleural fluid glucose assessment should be performed where pleural infection is possible. (B)

The presence of frank pus is diagnostic of an empyema and therefore, following aspiration, the appearance of the pleural fluid should be recorded. The $\mathrm{pH}$ of the pleural fluid of all nonpurulent aspirates should be measured immediately. Protein 
concentration and microbiological culture analysis should be routinely requested on all initial samples. Pleural fluid cytology and acid/alcohol fast bacilli analysis for mycobacteria should be performed if clinically indicated. Further details are given in the BTS pleural investigation guideline.

Pleural fluid from parapneumonic effusions or empyema is an inflammatory exudate and absolute pleural fluid protein values are of no value in determining the likelihood of spontaneous resolution of the effusion or chest tube drainage requirements. ${ }^{17} 232487$ Polymorphonuclear (PMN) leucocytes dominate, but the total pleural fluid leucocyte count varies widely between simple effusions and empyemas. ${ }^{24}$ A predominance of lymphocytes in an exudate should raise the possibility of malignancy or tuberculosis.

Pleural fluid for $\mathrm{pH}$ analysis should be collected anaerobically (as the presence of air can falsely elevate pleural fluid $\mathrm{pH}$ values $^{92}$ ) in a heparinised blood gas syringe and then measured in a blood gas analyser. Physicians should be aware that lidocaine is acidic and can depress measured $\mathrm{pH}^{92}$ so a different syringe (devoid of residual lidocaine after local anaesthetic administration) should be used for pleural fluid sampling. ${ }^{92} 93$ It is not advisable and should not be necessary to put frank pus through a blood gas analyser as this already indicates a need for chest tube drainage of the effusion. However, where there is uncertainty about whether a turbid/cloudy fluid is infected, $\mathrm{pH}$ can be measured safely using a blood gas analyser. Extensive clinical experience of this technique, particularly in the USA, has shown it does not damage the blood gas analyser. Measurement of pleural fluid $\mathrm{pH}$ is unreliable when analysed by $\mathrm{pH}$ litmus paper or a $\mathrm{pH}$ meter, and these should not be considered an acceptable alternative to a blood gas analyser. $^{94} 95$

A patient with pleural infection requiring drainage will develop a pleural fluid acidosis associated with a rising $\mathrm{LDH}$ level and a falling glucose level. ${ }^{17} 2485$ Data from a systemic meta-analysis reviewing these criteria have justified their use. ${ }^{85}$ This report showed that a pleural fluid $\mathrm{pH}$ of $<7.2$ is also the single most powerful indicator to predict a need for chest tube drainage, and that pleural fluid LDH (>1000 IU/l) and glucose $(<3.4 \mathrm{mmol} / \mathrm{l})$ did not improve diagnostic accuracy. Where pleural fluid $\mathrm{pH}$ measurement is not available glucose and $\mathrm{LDH}$ should be measured, a pleural fluid glucose level $<3.4 \mathrm{mmol} / \mathrm{l}$ may be used as an alternative marker to indicate a need for chest drain insertion. However, pleural fluid glucose may be lowered in situations other than pleural infection, such as rheumatoid effusions, and this should be borne in mind when interpreting the result.

Studies have shown that non-purulent collections with biochemical evidence of infection are likely to require chest tube drainage for adequate resolution of sepsis. 17212224252859778586

Occasionally a pleural fluid $\mathrm{pH}$ of $>7.6$ will be obtained in a complicated parapneumonic effusion as a result of infection with Proteus spp. Its ability to produce ammonia by urea splitting can produce alkalotic fluid. ${ }^{96}$

If a single pleural fluid sample appears out of context with the clinical status of the patient and the ultrasound appearances, it may be of value to repeat the aspiration. A small series of multiple locule sampling showed that the biochemistry may be different in different locules. ${ }^{97}$

Pleural fluid cytokine and/or inflammatory mediator levels (eg, IL-8, TNF $\boldsymbol{\alpha}$, vascular endothelial growth factor or CRP) may be useful to differentiate complicated parapneumonic effusions from other exudative collections. ${ }^{98-101}$ Further studies are required to elicit their exact role.
Indications for pleural fluid drainage in pleural infection

- Patients with frankly purulent or turbid/cloudy pleural fluid on sampling should receive prompt pleural space chest tube drainage. (B)

The presence of frankly purulent or turbid/cloudy fluid on pleural aspiration indicates the need for prompt chest tube drainage. ${ }^{17} 248586$ Purulent fluid is more frequent in patients who fail chest tube drainage and require surgery or who die. ${ }^{57}$

- The presence of organisms identified by Gram stain and/or culture from a non-purulent pleural fluid sample indicates that pleural infection is established and should lead to prompt chest tube drainage. (B)

The presence of organisms identified by positive Gram stain indicates bacterial invasion and implies progression from a simple effusion into a complicated parapneumonic effusion and hence the need for chest tube drainage. ${ }^{17} 248586$ However, some frankly purulent or culture-positive parapneumonic effusions due to $S$ pneumoniae may resolve with antibiotics alone, avoiding chest tube drainage. ${ }^{18} 87$ Decisions regarding pleural drainage should be made on an individual basis.

- Pleural fluid $\mathrm{pH}<7.2$ in patients with suspected pleural infection indicates a need for chest tube drainage. (B)

- Parapneumonic effusions that do not fulfil any of these criteria for chest tube drainage could be treated with antibiotics alone provided clinical progress is good. (B)

- Poor clinical progress during treatment with antibiotics alone should lead to prompt patient review, repeat pleural fluid sampling and probably chest tube drainage. (B)

Some patients with an initial pleural $\mathrm{pH}>7.2$ will fail to resolve their sepsis syndrome and will need chest tube drainage and even subsequent surgery. ${ }^{57}$ These occasional cases confirm that, while pleural $\mathrm{pH}$ is adequately specific in predicting the need for pleural drainage, it is less than $100 \%$ sensitive ${ }^{57}$ and does not accurately predict mortality or eventual need for surgical intervention. ${ }^{17} 57$ One reason for this is the heterogeneity of the biochemical characteristics in multiloculated effusions, such that sampling different infected locules can result in markedly different indices of disease severity. ${ }^{97}$ Unsatisfactory clinical progress therefore indicates a need for repeated pleural fluid sampling and possible chest tube drainage.

- Patients with a loculated pleural collection should receive early chest tube drainage. (C)

- Large non-purulent effusions could be drained by aspiration and/or chest tube if required for symptomatic benefit. (C)

When needle aspiration is straightforward, it may occasionally be possible to remove all the fluid at initial pleural fluid aspiration. In some cases the fluid will not re-accumulate and no further intervention will be required.

The presence of loculation on chest radiography or ultrasonography 2477102 is associated with a poorer outcome and may be an additional indication for early chest tube drainage. Larger pleural collections ( $>40 \%$ of the hemithorax) may be more likely to require surgery. ${ }^{1} 102$

\section{Chest tube drainage}

- A small-bore catheter 10-14 F will be adequate for most cases of pleural infection. However, there is no consensus on the size of the optimal chest tube for drainage. (C)

- If a small-bore flexible catheter is used, regular flushing is recommended to avoid catheter blockage. (C) 
- Chest tube insertion should be performed under imaging guidance wherever possible. (D)

Chest tube insertion should be performed in line with the BTS pleural procedures guidelines ${ }^{103}$ (see page iib1) and recent National Patient Safety Agency recommendations. ${ }^{88}$ Image guidance should be used whenever available, particularly as many infected effusions will be loculated.

The clinical outcome of patients with pleural infection treated with differing sized chest drains has not been addressed in a randomised controlled trial and there remains no clinical consensus on the optimal choice, with widely differing opinions between the medical and surgical specialities. Traditionally, closed chest tube drainage of pus from the pleural cavity has been via large-bore $(>28 \mathrm{~F})$ chest tubes inserted without radiological guidance. More recently, flexible small-bore catheters (10-14 F) have been employed, which are easier and less traumatic to insert and may be more comfortable for the patient.

In a large randomised trial assessing intrapleural fibrinolytic agents, subanalysis revealed no increased efficacy with large-bore tubes compared with small-bore drains. ${ }^{84}$ Previously published data suggest that image-guided small-bore catheters can have a good outcome, both as the initial drainage procedure ${ }^{104-108}$ and as a rescue treatment when larger tubes have failed. ${ }^{104-111}$ $10-14 \mathrm{~F}$ catheters are popular in these series and have a low complication rate. ${ }^{71} 105107111112$ There is, however, still a substantial body of opinion, based on anecdotal clinical experience, which considers large-bore tubes to be more effective for draining thick pus. Sound clinical trials are needed to clarify the optimal chest tube size.

No randomised controlled trial data exist evaluating optimal drain management issues such as flushing and drain suction. In most studies assessing small-bore catheters both flushing and suction were used, ${ }^{71} 104105107108111113$ which may improve drainage efficiency by reducing blockage of the catheter from fibrinous debris. Regular flushing (eg, 20-30 ml saline every $6 \mathrm{~h}$ via a three-way tap) is therefore recommended for small catheters, preferably administered by trained nurses. Flushing larger bore drains is technically more difficult as these do not routinely have three-way taps and disconnection for irrigation might encourage introduction of secondary infection.

Application of suction $\left(-20 \mathrm{~cm} \mathrm{H}_{2} \mathrm{O}\right)$ is employed in the belief that it improves drainage, but there is no adequate trial evidence or clinical consensus on which to base specific guidelines in this area. ${ }^{114} 115$

For further details on insertion of intercostal chest drains, readers are referred to the BTS pleural procedures guidelines ${ }^{103}$ and the section in this document on pleural procedures and thoracic ultrasound.

\section{Antibiotics}

- All patients should receive antibiotics targeted to treat the bacterial profile of modern pleural infection and based on local antibiotic policies and resistance patterns. (B)

- Antibiotics to cover anaerobic infection should be used in all patients except those with culture proven pneumococcal infection. (B)

- Macrolide antibiotics are not indicated unless there is objective evidence for or a high clinical index of suspicion of 'atypical' pathogens. (B)

-Where possible, antibiotic choice should be guided by bacterial culture results and advice from a microbiologist. (B)
- Penicillins, penicillins combined with $\beta$-lactamase inhibitors, metronidazole and cephalosporins penetrate the pleural space well. Aminoglycosides should be avoided. (B)

-When bacterial cultures are negative, antibiotics should cover both common community-acquired bacterial pathogens and anaerobic organisms. (B)

- Empirical antibiotic treatment for hospital-acquired empyema should include treatment for MRSA and anaerobic bacteria. (B)

- Intravenous antibiotics should be changed to oral therapy once there is clinical and objective evidence of improvement in sepsis. (D)

- Intrapleural antibiotics are not recommended. (D)

- Prolonged courses of antibiotics may be necessary and can often be administered as an outpatient after discharge. (D)

As soon as pleural infection is identified, all patients should receive antibiotic therapy and, where possible, this should be chosen based on results of pleural fluid or blood culture and sensitivities. Most patients with pleural infection will have had antibiotics already. However, despite this, in a recent randomised trial $54 \%$ of patients with pleural infection had positive pleural fluid cultures and $12 \%$ positive blood culture results. ${ }^{84}$ Those with positive blood cultures often had no other positive microbiology results, emphasising the importance of taking blood cultures from all patients with suspected pleural infection. ${ }^{84}$

A significant proportion of both aerobes and anaerobic organisms from pleuropulmonary infection may demonstrate resistance to penicillin, ${ }^{716} 117$ but $\beta$-lactams remain the agents of choice for $S$ pneumoniae ${ }^{118}$ and $S$ milleri infections. ${ }^{119} 120$ Aminopenicillins, penicillins combined with $\beta$-lactamase inhibitors (eg, co-amoxiclav, piperacillin-tazobactam) and cephalosporins show good penetration of the pleural space. ${ }^{34121-124}$ Aminoglycosides should be avoided as they have poor penetration into the pleural space and may be inactive in the presence of pleural fluid acidosis. $^{34}{ }^{125-128}$ There is no evidence that administering antibiotics directly into the pleural space offers any advantage.

In the absence of positive culture results, empirical antibiotics should be chosen to cover likely pathogenic organisms. There are a considerable number of reasonable drug combinations and the chosen regimen should reflect whether the infection was community- or hospital-acquired, local hospital policies and antibiotic resistance patterns.

In community-acquired infection, treatment with an aminopenicillin (eg, amoxicillin) will cover organisms such as $S$ pneumoniae and $H$ influenzae, ${ }^{129}$ but a $\beta$-lactamase inhibitor such as co-amoxiclav or metronidazole should also be given because of the frequent co-existence of penicillin-resistant aerobes including $S$ aureus and anaerobic bacteria. ${ }^{7117} 130$ A synergistic role of anaerobes with the $S$ milleri group of organisms has been postulated. ${ }^{131} 132$

Clindamycin achieves good penetration of the infected pleural space $^{126} 133134$ and offers adequate antimicrobial cover for these patients. Patients with a penicillin allergy can therefore be treated by clindamycin alone ${ }^{729}$ or in combination with ciprofloxacin or a cephalosporin. ${ }^{135}$ Chloramphenicol, carbapenems such as meropenem, third generation cephalosporins and broad-spectrum antipseudomonal penicillins such as piperacillin also have good anti-anaerobic activity and are alternative agents. ${ }^{116} 136$

Pleural effusions may occur in patients with Legionella pneumonia but are usually self-resolving. ${ }^{137}$ Although Legionella was not identified in a large recent series of UK adult pleural 
infections, ${ }^{2}$ it has rarely been reported as a cause of empyema ${ }^{138}$ and a macrolide antibiotic should be added in proven/suspected cases, although use of these antibiotics is not routinely recommended. Similarly, pleural effusions may occur in $5-20 \%$ of patients with pneumonia due to Mycoplasma pneumoniae. ${ }^{139} 140$ These are usually small reactive effusions which will resolve with suitable antibiotics, but diagnostic pleural fluid sampling may be needed to exclude a complicated parapneumonic effusion or empyema. In all cases, antibiotic regimens should be adjusted according to the subsequent culture results (while remembering that anaerobic pathogens are difficult to grow and having a low threshold for anti-anaerobic coverage).

In hospital-acquired empyema, usually secondary to nosocomial pneumonia, trauma or surgery, antibiotics should be chosen to treat both Gram-positive and Gram-negative aerobes and anaerobic organisms (see table 1). Recent studies show that there is a significant increase in MRSA infection causing hospital-acquired pneumonia and empyema, so empirical antibiotics for the latter should initially include cover for MRSA until microbiological results are available. ${ }^{2} 141-144$

Intravenous administration of antibiotics is often appropriate initially but can be changed to the oral route when objective clinical and biochemical improvement is seen. The duration of treatment for pleural infection has not been assessed in detailed clinical trials, however antibiotics are often continued for at least 3 weeks, again based on clinical, biochemical (eg, CRP) and radiological response.

\section{Intrapleural fibrinolytics}

- There is no indication for the routine use of intrapleural fibrinolytics in patients for pleural infection. (A)

Intrapleural fibrinolytic therapy was first used in $1949 .{ }^{11}$ More recently, observational series ${ }^{11}{ }^{145-169}$ and small randomised trials $^{149} 170-178$ showed these agents improved pleural fluid drainage, and it was therefore widely assumed they would improve long-term patient outcome. However, a recent large randomised trial showed that these short-term drainage benefits are not associated with reduced mortality, the frequency of surgery, the length of hospital stay or long-term radiological and lung function outcome. ${ }^{84}$ This trial used intrapleural streptokinase that was associated with an excess of immunological adverse reactions such as fever, leucocytosis and malaise, ${ }^{148} 156165179180$ but no excess of systemic or intrapleural bleeding and no systemic activation of the fibrinolytic cascade $^{84}$ in contrast to previous isolated reports of local pleural haemorrhage, ${ }^{156} 163168$ systemic bleeding ${ }^{153}$ and epistaxis ${ }^{156}$ associated with its administration. ${ }^{151}$ Thus, current evidence does not support the routine use of intrapleural fibrinolytic agents. On occasions, such treatment may be indicated for the physical decompression of multiloculated (and so tube drainageresistant) pleural fluid collections that are responsible for dyspnoea or respiratory failure if discussion with a thoracic surgeon identifies that either surgery is not immediately possible due to additional patient co-morbidity, the feasibility of transfer to a surgical unit or other clinical or logistical reasons.

Urokinase is non-antigenic but may still cause acute reactions (due to immediate hypersensitivity and histamine release) with fever ${ }^{150}$ and cardiac arrhythmia. ${ }^{181}$ There is a report of adult respiratory distress syndrome in a patient who received both streptokinase and urokinase for empyema drainage. ${ }^{182}$

Doses of fibrinolytics used in studies have varied but include streptokinase 250000 IU daily ${ }^{11} 145$ 147-149 151-157 160163165167 $169170173-176179$ or 250000 IU 12-hourly ${ }^{84} 151$ or urokinase 100000 IU daily ${ }^{170} 1711^{178}$ retained for $2-4 \mathrm{~h}$ in the pleural space.
There is currently interest in other intrapleural agents including combination therapy with fibrinolytics and fluid viscosity and biofilm-disrupting agents such as streptodornase and deoxyribonuclease (DNase). ${ }^{183}{ }^{184}$ In experimental/translational studies, this combination reduced infected pus viscosity when compared with fibrinolytics (streptokinase) alone and can disrupt infected biofilms. ${ }^{183-187}$ Such therapeutic combinations are currently in human clinical trials. Preliminary results from one of these trials suggests that a combination of intrapleural tPA and DNase may provide superior drainage to a fibrinolytic alone, but full publication of these results is awaited.

\section{Timing of chest drain removal in pleural infection}

Removal of the chest drain is appropriate after radiological confirmation of successful pleural drainage-that is, reduction in the size of the pleural collection on the chest x-ray or thoracic ultrasound-and objective evidence of sepsis resolution - that is, improvement in temperature and clinical condition and decreasing inflammatory markers (eg, CRP). Inpatient observation for $24 \mathrm{~h}$ after drain removal is usual, although a longer period of rehabilitation may be necessary as most patients will have been unwell and in hospital for a prolonged period.

\section{Persistent sepsis and pleural collection}

- Patients with persistent sepsis and a residual pleural collection should undergo further radiological imaging. (C)

- Patients with persistent sepsis and a residual pleural collection should be discussed with a thoracic surgeon to consider all possible surgical options available. (D)

In patients who do not respond to antibiotics and chest drainage with ongoing signs of sepsis in association with a persistent pleural collection, the diagnosis should be reviewed and a further chest x-ray and CT scan or thoracic ultrasound performed. Contrast-enhanced thoracic CT scanning more accurately identifies chest tube position, the anatomy of the effusion, presence of pleural thickening and may also identify endobronchial obstruction and mediastinal pathology. ${ }^{188-193}$ Pleural thickening may represent development of a fibrinous 'peel' which may prevent lung re-expansion and hence pleural apposition regardless of adequacy of fluid drainage. ${ }^{188} 192 \quad 194-196$ CT scanning cannot accurately differentiate early from late fibrinopurulent stage disease, $^{82}$ and pleural thickness on the CT scan does not appear to predict long-term outcome from tube drainage. ${ }^{57} \mathrm{~A}$ pleural 'peel' may resolve over several weeks and persisting with medical therapy over this period in stable patients may prevent the need for surgery. ${ }^{196}$ Residual calcification, ${ }^{82}$ thickening of extrapleural tissues $^{82}$ and pleural scarring ${ }^{196}$ may be seen on imaging long after resolution of an empyema.

\section{Patients with persistent sepsis}

- Patients should receive surgical treatment if they have persisting sepsis in association with a persistent pleural collection, despite chest tube drainage and antibiotics. (C)

- Failure of chest tube drainage and antibiotics should prompt early discussion with a thoracic surgeon. (C)

No objective criteria exist to define the point at which surgical intervention for control of pleural infection is required and the decision to operate on a patient remains subjective. Although previous observational studies have indicated that patients with purulent fluid ${ }^{57}$ and/or loculations ${ }^{102}$ at presentation are more likely to require surgery, many of these patients will settle without an operation and recent data indicate these features are not predictive. ${ }^{84} 197$ Patients should be considered for surgery if they have ongoing signs of sepsis in association with a persistent 
pleural collection despite drainage and antibiotics. Failure of sepsis to resolve within 5-7 days ${ }^{39} 198$ is suggested as an appropriate period following which a surgical opinion should be sought. Discussion with a thoracic surgeon should be considered in all cases failing to respond.

VATS is increasingly used as first-line therapy although open thoracic drainage or thoracotomy and decortication remain alternative techniques. The type of procedure performed will depend on many factors including patient age and comorbidity, surgeons' preferences and local equipment availability. The choice of surgical procedure is beyond the remit of these guidelines and is not considered further.

Two small unblinded randomised trials have directly compared surgical and medical therapy. Wait et al ${ }^{12}$ studied 20 patients with pleural infection who were suitable for general anaesthesia and randomised them to receive either immediate VATS or chest tube insertion (by junior resident medical staff) with additional instillation of intrapleural streptokinase for 3 days. The surgical group had higher primary treatment success (10/11 patients) and all streptokinase medical failures (5/9 patients) were salvaged by surgery without requiring thoracotomy. ${ }^{12}$ Surgical patients also had a shorter drainage period (5.8 vs 9.8 days) and hospital stay (8.7 vs 12.8 days). The results of this study are of doubtful robustness as the trial was very small, had an unusually high clinical failure rate in the control limb (55\%) which explains the positive result, and was not blinded and so open to bias.

Bilgin et al ${ }^{199}$ randomised 70 patients with pleural infection to immediate VATS under local anaesthesia with sedation $(n=29)$ or general anaesthesia if this was not tolerated $(n=6)$ versus chest tube drainage $(n=35)$. Both groups received antibiotic therapy. In the VATS group, initial treatment success was achieved in $82.8 \%$ (ie, no indication for subsequent open thoracotomy and decortication) compared with $62.9 \%$ in the tube drainage group. The mean hospital stay was 8.3 days for the VATS group and 12.8 days in the tube drainage arm $(p<0.05) .{ }^{199}$ Interpretation of the results, however, should be carefully considered as the authors did not clearly specify the primary outcome measure and the indications prompting further surgical intervention were highly subjective. Further appropriately powered and blinded trials are needed in this area.

- The choice of antibiotic should be reviewed and a prolonged course administered where appropriate. (D)

- A thoracic surgeon should be involved in assessment of suitability for anaesthesia. Less radical surgical interventions including rib resection and placement of a large-bore drain may be considered in frail patients depending on surgical expertise and access and can be performed in some cases under local anaesthetic or with epidural anaesthesia. (C)

- In patients with ineffective effusion drainage and persistent sepsis who are unable to tolerate general anaesthesia, re-imaging of the thorax and placement of a further image-guided small-bore catheter, a largerbore chest tube or intrapleural fibrinolytic could be considered after discussion with a thoracic surgeon. (D)

- For some patients, palliative treatment and active symptom control measures will be appropriate. (D)

Ineffective chest tube drainage and persistent sepsis in patients unfit for radical treatment can be approached by a number of 'less invasive' options. Re-imaging the thorax and placement of further image-guided small-bore catheters may drain loculated collections ${ }^{105-109111}$ and larger bore chest tubes can be tried for 'thick' pus. ${ }^{112}$ Alternatively, patients may proceed to surgical rib resection and open drainage under general or local anaesthesia; continued liaison with a thoracic surgeon should continue in achieving optimal management. The prolonged period (often months) of recovery following this procedure can contribute to increased patient morbidity and this must be discussed with patients during procedural consent.

For some patients with empyema who are unfit for radical treatment, further drainage may not be acceptable and, in these cases, ongoing sepsis and impaired respiratory function can lead to an unrelenting decline and subsequent death. When these patients are identified, palliative symptom control delivered by a multidisciplinary team may be appropriate.

\section{Bronchoscopy}

- Bronchoscopy should only be performed in patients where there is a high index of suspicion of bronchial obstruction. (C)

The role of bronchoscopy in patients with empyema has not been addressed specifically by any studies. In one series, 43/119 patients $(36 \%)$ with empyema underwent bronchoscopy and tumour was found in only five patients. ${ }^{1}$ Bronchoscopy is usually performed at the time of surgery by most thoracic surgeons but, again, only a small number of these patients have obstructing tumour predisposing to their empyema. ${ }^{40}$ Bronchoscopy is therefore only recommended where there is a high index of suspicion for bronchial obstruction-for example, a mass or volume loss on radiographic imaging or a history of possible foreign body which may predispose to the pleural infection itself.

\section{Follow-up}

- All patients with empyema and pleural infection require outpatient follow-up. (D)

Outpatient follow-up with a repeat chest x-ray and inflammatory markers should be arranged for all patients, often within 4 weeks following discharge, and continued outpatient care may be required for several months depending on progress. Persistent elevation of patients' inflammatory markers should prompt further imaging and be interpreted in combination with their clinical status. Patients should be advised to return for prompt medical attention if recurrent symptoms develop since late relapse of pleural infection is well recognised.

\section{Prognosis in pleural infection}

The long-term survival of patients with pleural infection is good if prompt treatment is initiated. In a series of 85 patients followed for up to 4 years, the mortality was $14 \%$ and all deaths occurred within the first 400 days after drainage. ${ }^{57}$ Deaths were usually due to comorbid conditions and not directly due to sepsis from the empyema.

No reliable clinical, radiological or pleural fluid characteristics accurately determine patients' prognosis at initial presentation. Hypoalbuminaemia, the presence of loculated fluid and anaerobic infections have been related to adverse outcome in previous studies $^{17677}$ although not in recent reports. ${ }^{2} 57$

Long-term sequelae of pleural empyema may include residual pleural thickening (up to $13 \%$ of patients). ${ }^{200}$ This is not usually associated with functional impairment although, rarely, extensive incapacitating pleural fibrosis may develop (fibrothorax). ${ }^{135200201}$ Surgical decortication may occasionally provide symptomatic benefit for patients with a fibrothorax. Pleural calcification, bronchopleural fistula formation and development of empyema necessitans (disruption of the parietal pleura with spontaneous discharge of pleural contents evident under the chest wall) are other rare complications. 


\section{Pyothorax-associated lymphoma}

Pleural lymphoma is rare. It may arise in approximately $2 \%$ of patients with a long-standing pyothorax (>20 years), usually following induction of an artificial pneumothorax for tuberculosis. $^{202-211}$ It predominantly occurs in Japanese populations, with few reports of cases from the Western world. ${ }^{202} 210$ Histologically, it is a non-Hodgkin's lymphoma with a distinctive $\mathrm{B}$ cell phenotype. The exact pathogenesis remains unclear, however there is a recognised association with Epstein-Barr virus infection. ${ }^{203} 207208211212$

Competing interests No member of the Guideline Group is aware of any competing interests.

Provenance and peer review The draft guideline was available for online public consultation (July/August 2009) and presented to the BTS Winter Meeting (December 2009). Feedback was invited from a range of stakeholder institutions (see Introduction). The draft guideline was reviewed by the BTS Standards of Care Committee (September 2009)

\section{REFERENCES}

1. Ferguson AD, Prescott RJ, Selkon JB, et al. The clinical course and management of thoracic empyema. $0 \mathrm{~J}$ Med 1996;89:285-9. (3).

2. Maskell NA, Batt S, Hedley EL, et al. The bacteriology of pleural infection by genetic and standard methods and its mortality significance. Am J Respir Crit Care Med 2006;174:817-23. $(\mathbf{1}++)$.

3. Finley C, Clifton J, Fitzgerald JM, et al. Empyema: an increasing concern in Canada. Can Respir J 2008:15:85-9. (2+).

4. Meyer JA. Gotthard Bulau and closed water-seal drainage for empyema, 1875-1891. Ann Thorac Surg 1989;48:597-9. (4)

5. Peters RM. Empyema thoracis: historical perspective. Ann Thorac Surg 1989;48:306-8. (4)

6. Heffner JE. Diagnosis and management of thoracic empyemas. Curr Opin Pulm Med 1996;2:198-205. (4).

7. Bartlett JG. Anaerobic bacterial infections of the lung and pleural space. Clin Infect Dis 1993;16(Suppl 4):S248-55. (4).

8. Stiles $\mathbf{0 R}$, Lindesmith GG, Tucker BL, et al. Pleural empyema in children. Ann Thorac Surg 1970:10:37-44. (3)

9. Alfageme I, Munoz F, Pena N, et al. Empyema of the thorax in adults. Etiology, microbiologic findings, and management. Chest 1993;103:839-43. (3).

10. Wallenhaupt SL. Surgical management of thoracic empyema. J Thorac Imaging 1991;6:80-8. (3)

11. Tilllett WS, Sherry S. The effect in patients of streptococcal fibrinolysin and streptococcal desoxyribonuclease on fibrinous, purulent, and sanguinous pleural exudations. J Clin Invest 1949;28:173-90. (3)

12. Wait MA, Sharma $S$, Hohn J, et al. A randomized trial of empyema therapy. Chest 1997:111:1548-51. (1-).

13. Farjah F, Symons RG, Krishnadasan B, et al. Management of pleural space infections: a population-based analysis. J Thorac Cardiovasc Surg 2007;133:346-51. (2+)

14. Wang NS. Anatomy of the pleura. Clin Chest Med 1998;19:229-40. (4)

15. Agostoni E, Zocchi L. Mechanical coupling and liquid exchanges in the pleural space. Clin Chest Med 1998;19:241-60. (4).

16. Trotter CL, Stuart JM, George R, et al. Increasing hospital admissions for pneumonia, England. Emerg Infect Dis 2008;14:727-33. (3)

17. Light RW, Girard WM, Jenkinson SG, et al. Parapneumonic effusions. Am J Med 1980;69:507-12. $(2+)$

18. Taryle DA, Potts DE, Sahn SA. The incidence and clinical correlates of parapneumonic effusions in pneumococcal pneumonia. Chest 1978;74:170-3. (3)

19. American Thoracic Society. Management of nontuberculous empyema: a statement of the subcommittee on surgery. Am Rev Respir Dis 1962;935-6. (4).

20. Aleman C, Alegre J, Monasterio J, et al. Association between inflammatory mediators and the fibrinolysis system in infectious pleural effusions. Clin Sci (Lond) 2003; 105:601-7. (3).

21. Kroegel C, Antony VB. Immunobiology of pleural inflammation: potential implications for pathogenesis, diagnosis and therapy. Eur Respir J 1997;10:2411-18. (4)

22. Good JT Jr, Taryle DA, Maulitz RM, et al. The diagnostic value of pleural fluid pH. Chest 1980;78:55-9. (3).

23. Light RW, MacGregor Ml, Ball WC Jr, et al. Diagnostic significance of pleural fluid $\mathrm{pH}$ and PCO2. Chest 1973:64:591-6. (2+).

24. Potts DE, Levin DC, Sahn SA. Pleural fluid pH in parapneumonic effusions. Chest 1976; 70:328-31. (2+)

25. Potts DE, Taryle DA, Sahn SA. The glucose-pH relationship in parapneumonic effusions. Arch Intern Med 1978;138:1378-80. (2+)

26. Sasse SA, Causing LA, Mulligan ME, et al. Serial pleural fluid analysis in a new experimental model of empyema. Chest 1996;109:1043-8. (2+).

27. Idell S, Girard W, Koenig KB, et al. Abnormalities of pathways of fibrin turnover in the human pleural space. Am Rev Respir Dis 1991:144:187-94. (2+)

28. Sahn SA, Reller LB, Taryle DA, et al. The contribution of leukocytes and bacteria to the low pH of empyema fluid. Am Rev Respir Dis 1983:128:811-15. (2+).
29. Ali I, Unruh H. Management of empyema thoracis. Ann Thorac Surg 1990;50:355-9. (3)

30. Ashbaugh DG. Empyema thoracis. Factors influencing morbidity and mortality. Chest 1991:99:1162-5. (3).

31. Bartlett JG, Gorbach SL, Thadepalli $\mathrm{H}$, et al. Bacteriology of empyema. Lancet 1974;1:338-40. (3).

32. Brook I, Frazier EH. Aerobic and anaerobic microbiology of empyema. A retrospective review in two military hospitals. Chest 1993;103:1502-7. (3).

33. Galea JL, De Souza A, Beggs D, et al. The surgical management of empyema thoracis. J R Coll Surg Edinb 1997;42:15-18. (3)

34. Hughes CE, Van Scoy RE. Antibiotic therapy of pleural empyema. Semin Respir Infect 1991:6:94-102. (4).

35. Landreneau RJ, Keenan RJ, Hazelrigg SR, et al. Thoracoscopy for empyema and hemothorax. Chest 1996;109:18-24. (3).

36. LeMense GP, Strange C, Sahn SA. Empyema thoracis. Therapeutic management and outcome. Chest 1995;107:1532-7. (3)

37. Lemmer JH, Botham MJ, Orringer MB. Modern management of adult thoracic empyema. J Thorac Cardiovasc Surg 1985;90:849-55. (3)

38. Mandal AK, Thadepalli $\mathrm{H}$. Treatment of spontaneous bacterial empyema thoracis J Thorac Cardiovasc Surg 1987:94:414-18. (3).

39. Mavroudis C, Symmonds JB, Minagi $\mathrm{H}$, et al. Improved survival in management of empyema thoracis. J Thorac Cardiovasc Surg 1981;82:49-57. (3).

40. Sherman MM, Subramanian V, Berger RL. Managment of thoracic empyema. Am J Surg 1977; 133:474-9. (3).

41. Smith JA, Mullerworth MH, Westlake GW, et al. Empyema thoracis: 14-year experience in a teaching center. Ann Thorac Surg 1991;51:39-42. (3).

42. Storm HK, Krasnik M, Bang K, et al. Treatment of pleural empyema secondary to pneumonia: thoracocentesis regimen versus tube drainage.

Thorax 1992;47:821-4. (3)

43. Van WC III, Narrod J, Hopeman A. The role of early limited thoracotomy in the treatment of empyema. J Thorac Cardiovasc Surg 1988;96:436-9. (3).

44. Varkey B, Rose HD, Kutty CP, et al. Empyema thoracis during a ten-year period Analysis of 72 cases and comparison to a previous study (1952 to 1967) Arch Intern Med 1981;141:1771-6. (3)

45. Chen KY, Hsueh PR, Liaw YS, et al. A 10-year experience with bacteriology of acute thoracic empyema: emphasis on Klebsiella pneumoniae in patients with diabetes mellitus. Chest 2000;117:1685-9. (3).

46. Civen R, Jousimies-Somer $\mathrm{H}$, Marina $\mathrm{M}$, et al. A retrospective review of cases of anaerobic empyema and update of bacteriology. Clin Infect Dis 1995;20(Suppl 2):S224-9. (3).

47. Lin YC, Chen HJ, Liu YH, et al. A 30-month experience of thoracic empyema in a tertiary hospital: emphasis on differing bacteriology and outcome between the medical intensive care unit (MICU) and medical ward. South Med $J$ 2008;101:484-9. (3).

48. Tu CY, Hsu WH, Hsia TC, et al. The changing pathogens of complicated parapneumonic effusions or empyemas in a medical intensive care unit. Intensive Care Med 2006;32:570-6. (3).

49. Mandal AK, Thadepalli H, Mandal AK, et al. Outcome of primary empyema thoracis: therapeutic and microbiologic aspects. Ann Thorac Surg 1998:66:1782-6. (3)

50. Rahman NM, Chapman SJ, Davies RJ. The approach to the patient with a parapneumonic effusion. Clin Chest Med 2006;27:253-66. (4).

51. Ko SC, Chen KY, Hsueh PR, et al. Fungal empyema thoracis: an emerging clinical entity. Chest 2000;117:1672-8. (3)

52. Dhiensiri T, Puapairoj S, Susaengrat W. Pulmonary melioidosis: clinical-radiologic correlation in 183 cases in northeastern Thailand. Radiology 1988;166:711-15. (3)

53. Lyche KD, Jensen WA. Pleuropulmonary amebiasis. Semin Respir Infect 1997:12:106-12. (4).

54. Prasad R, Verma SK. A study of anaerobic infection in patients with empyema thoracis. J Int Med India 2005;8:75-9. (3).

55. Saglani S, Harris KA, Wallis $C$, et al. Empyema: the use of broad range $16 S$ rDNA PCR for pathogen detection. Arch Dis Child 2005;90:70-3. (2+).

56. Cham CW, Haq SM, Rahamim J. Empyema thoracis: a problem with late referral? Thorax 1993:48:925-7. (3)

57. Davies CW, Kearney SE, Gleeson FV, et al. Predictors of outcome and long-term survival in patients with pleural infection. Am J Respir Crit Care Med 1999;160:1682-7. (3)

58. Heffner JE, McDonald J, Barbieri C, et al. Management of parapneumonic effusions. An analysis of physician practice patterns. Arch Surg 1995; 130:433-8. (3).

59. Sasse S, Nguyen TK, Mulligan M, et al. The effects of early chest tube placement on empyema resolution. Chest 1997:111:1679-83. (1+).

60. Blosser SA, Zimmerman HE, Stauffer JL. Do autopsies of critically ill patients reveal important findings that were clinically undetected? Crit Care Med 1998;26:1332-6. (3).

61. Davidson BL. Risk assessment and prophylaxis of venous thromboembolism in acutely and/or critically ill patients. Haemostasis 2000;30(Suppl 2):77-81. (4).

62. Dentali F, Douketis JD, Gianni M, et al. Meta-analysis: anticoagulant prophylaxis to prevent symptomatic venous thromboembolism in hospitalized medical patients. Ann Intern Med 2007:146:278-88. (1+).

63. Geerts W, Selby R. Prevention of venous thromboembolism in the ICU. Chest 2003;124:357S-63. $(\mathbf{1 + 1}$. 
64. Geerts WH, Pineo GF, Heit JA, et al. Prevention of venous thromboembolism: the Seventh ACCP Conference on Antithrombotic and Thrombolytic Therapy. Chest 2004;126:338-400S. (1 -)

65. Leizorovicz A, Cohen AT, Turpie AG, et al. Randomized, placebo-controlled trial of dalteparin for the prevention of venous thromboembolism in acutely ill medical patients. Circulation 2004:110:874-9. $(\mathbf{1 + +})$

66. Lim WS, Baudouin SV, George RC, et al. BTS guidelines for the management of community acquired pneumonia in adults: update 2009. Thorax 2009;64(Suppl 3): iii1-55. $(\mathbf{1}+\mathbf{+})$.

67. Hansson LO, Hedlund JU, Ortqvist AB. Sequential changes of inflammatory and nutritional markers in patients with community-acquired pneumonia. Scand J Clin Lab Invest 1997:57:111-18. (3).

68. Ortqvist A, Hedlund J, Wretlind B, et al. Diagnostic and prognostic value of interleukin-6 and C-reactive protein in community-acquired pneumonia. Scand J Infect Dis 1995:27:457-62. (3).

69. Chalmers JD, Singanayagam A, Hill AT. C-reactive protein is an independent predictor of severity in community-acquired pneumonia. Am J Med 2008; 121:219-25. $(2+)$.

70. Chalmers JD, Singanayagam A, Murray MP, et al. Risk factors for complicated parapneumonic effusion and empyema on presentation to hospital with communityacquired pneumonia. Thorax 2009;64:556-8. (3)

71. Stavas J, vanSonnenberg E, Casola G, et al. Percutaneous drainage of infected and noninfected thoracic fluid collections. J Thorac Imaging 1987:2:80-7. (4).

72. Eibenberger KL, Dock WI, Ammann ME, et al. Quantification of pleural effusions: sonography versus radiography. Radiology 1994;191:681-4. (2+).

73. Sahn SA. State of the art. The pleura. Am Rev Respir Dis 1988;138:184-234. (4).

74. Strange C. Effusions caused by gastrointestinal disease. In: Light RW, Lee YCG, eds. Textbook of pleural diseases. London: Hodder Arnold, 2008:465-70. (4)

75. Yang PC, Luh KT, Chang DB, et al. Value of sonography in determining the nature of pleural effusion: analysis of 320 cases. AJR Am J Roentgenol 1992;159:29-33. (3)

76. Chen KY, Liaw YS, Wang HC, et al. Sonographic septation: a useful prognostic indicator of acute thoracic empyema. J Ultrasound Med 2000;19:837-43. (2+)

77. Himelman RB, Callen PW. The prognostic value of loculations in parapneumonic pleural effusions. Chest 1986;90:852-6. (3).

78. Muller NL. Imaging of the pleura. Radiology 1993;186:297-309. (4)

79. Stark DD, Federle MP, Goodman PC, et al. Differentiating lung abscess and empyema: radiography and computed tomography. AJR Am J Roentgenol 1983:141:163-7. (3)

80. Aquino SL, Webb WR, Gushiken BJ. Pleural exudates and transudates: diagnosis with contrast-enhanced CT. Radiology 1994;192:803-8. (3)

81. Takasugi JE, Godwin JD, Teefey SA. The extrapleural fat in empyema: CT appearance. Br J Radiol 1991;64:580-3. (3)

82. Waite RJ, Carbonneau RJ, Balikian JP, et al. Parietal pleural changes in empyema: appearances at CT. Radiology 1990;175:145-50. (3)

83. Kearney SE, Davies CW, Davies RJ, et al. Computed tomography and ultrasound in parapneumonic effusions and empyema. Clin Radiol 2000:55:542-7. (3).

84. Maskell NA, Davies CW, Nunn AJ, et al. U.K. Controlled trial of intrapleural streptokinase for pleural infection. N Engl J Med 2005;352:865-74. (1++).

85. Heffner JE, Brown LK, Barbieri C et al. Pleural fluid chemical analysis in parapneumonic effusions. A meta-analysis. Am J Respir Crit Care Med 1995; 151:1700-8. (1+).

86. Light RW. A new classification of parapneumonic effusions and empyema. Chest 1995;108:299-301. (4)

87. Poe RH, Marin MG, Israel RH, et al. Utility of pleural fluid analysis in predicting tube thoracostomy/decortication in parapneumonic effusions. Chest 1991;100:963-7. (3)

88. National Patient Safety Agency (NPSA). Rapid Response Report: Risks of chest drain insertion (Reference NPSA/2008/RRR03). 2008:1-10. (4).

89. Diacon AH, Brutsche MH, Soler M. Accuracy of pleural puncture sites: a prospective comparison of clinical examination with ultrasound. Chest 2003;123:436-41. (2+).

90. Jones PW, Moyers JP, Rogers JT, et al. Ultrasound-guided thoracentesis: is it a safer method? Chest 2003;123:418-23. (2+).

91. Mattison LE, Coppage L, Alderman DF, et al. Pleural effusions in the medical ICU: prevalence, causes, and clinical implications. Chest 1997:111:1018-23. (3).

92. Rahman NM, Mishra EK, Davies HE, et al. Clinically important factors influencing the diagnostic measurement of pleural fluid $\mathrm{pH}$ and glucose. Am J Respir Crit Care Med 2008;178:483-90. (2+)

93. Jimenez CD, Diaz G, Perez-Rodriguez E, et al. Modification of pleural fluid pH by local anesthesia. Chest 1999;116:399-402. (2+).

94. Cheng DS, Rodriguez RM, Rogers J, et al. Comparison of pleural fluid $\mathrm{pH}$ values obtained using blood gas machine, $\mathrm{pH}$ meter, and $\mathrm{pH}$ indicator strip. Chest 1998;114:1368-72. (2+)

95. Lesho EP, Roth BJ. Is pH paper an acceptable, low-cost alternative to the blood gas analyzer for determining pleural fluid $\mathrm{pH}$ ? Chest 1997;112:1291-2. (2+).

96. Pine JR, Hollman JL. Elevated pleural fluid pH in Proteus mirabilis empyema. Chest 1983;84:109-11. (3)

97. Maskell NA, Gleeson FV, Darby M, et al. Diagnostically significant variations in pleural fluid pH in loculated parapneumonic effusions. Chest 2004;126:2022-4. (3).

98. Akarsu S, Kurt AN, Dogan $Y$, et al. The differential diagnostic values of cytokine levels in pleural effusions. Mediat Inflamm 2005;2005:2-8. (3).
99. Chen SC, Chen W, Hsu WH, et al. Role of pleural fluid C-reactive protein concentration in discriminating uncomplicated parapneumonic pleural effusions from complicated parapneumonic effusion and empyema. Lung 2006;184:141-5. (2+)

100. Porcel JM, Vives M, Esquerda A. Tumor necrosis factor-alpha in pleural fluid: a marker of complicated parapneumonic effusions. Chest 2004;125:160-4. (2+)

101. Thickett DR, Armstrong L, Millar AB. Vascular endothelial growth factor (VEGF) in inflammatory and malignant pleural effusions. Thorax 1999;54:707-10. (2+).

102. Huang HC, Chang HY, Chen CW, et al. Predicting factors for outcome of tube thoracostomy in complicated parapneumonic effusion for empyema. Chest 1999;115:751-6. (3)

103. British Thoracic Society. Guidance for the local implementation of local trust policies for the safe insertion of chest drains for pleural effusions in adults, following the NPSA Rapid Response Report. http://www.brit-thoracic.org.uk/ Portals/0/Clinical\%20Information/Pleural\%20Disease/chestdrain-adults.pdf (accessed 2009). (4).

104. Merriam MA, Cronan JJ, Dorfman GS, et al. Radiographically guided percutaneous catheter drainage of pleural fluid collections. AJR Am J Roentgenol 1988;151:1113-16. (3)

105. Silverman SG, Mueller PR, Saini S, et al. Thoracic empyema: management with image-guided catheter drainage. Radiology 1988;169:5-9. (3)

106. Stavas J, vanSonnenberg E, Casola G, et al. Percutaneous drainage of infected and noninfected thoracic fluid collections. J Thorac Imaging 1987:2:80-7. (3).

107. Ulmer JL, Choplin RH, Reed JC. Image-guided catheter drainage of the infected pleural space. J Thorac Imaging 1991;6:65-73. (4)

108. Westcott JL. Percutaneous catheter drainage of pleural effusion and empyema. AJR Am J Roentgenol 1985;144:1189-93. (3)

109. Crouch JD, Keagy BA, Delany DJ. "Pigtail" catheter drainage in thoracic surgery. Am Rev Respir Dis 1987:136:174-5. (3)

110. Hunnam GR, Flower CD. Radiologically-guided percutaneous catheter drainage of empyemas. Clin Radiol 1988;39:121-6. (3).

111. vanSonnenberg $\mathbf{E}$, Nakamoto SK, Mueller PR, et al. CT- and ultrasound-guided catheter drainage of empyemas after chest-tube failure. Radiology 1984;151:349-53. (3)

112. Klein JS, Schultz S, Heffner JE. Interventional radiology of the chest: image-guided percutaneous drainage of pleural effusions, lung abscess, and pneumothorax. AJR Am J Roentgenol 1995;164:581-8. (4).

113. Lee KS, Im JG, Kim YH, et al. Treatment of thoracic multiloculated empyemas with intracavitary urokinase: a prospective study. Radiology 1991;179:771-5. (3)

114. Miller KS, Sahn SA. Chest tubes. Indications, technique, management and complications. Chest 1987;91:258-64. (4).

115. Munnell ER. Thoracic drainage. Ann Thorac Surg 1997;63:1497-502. (4)

116. Bartlett JG. Antibiotics in lung abscess. Semin Respir Infect 1991;6:103-11. (4)

117. Neild JE, Eykyn SJ, Phillips I. Lung abscess and empyema. $0 \mathrm{~J}$ Med 1985;57:875-82. (3).

118. Minton EJ, Macfarlane JT. Antibiotic resistant Streptococcus pneumoniae Thorax 1996;51(Suppl 2):S45-S50. (4).

119. Jerng JS, Hsueh PR, Teng LJ, et al. Empyema thoracis and lung abscess caused by viridans streptococci. Am J Respir Crit Care Med 1997;156:1508-14. (3)

120. Wong CA, Donald F, Macfarlane JT. Streptococcus milleri pulmonary disease: a review and clinical description of 25 patients. Thorax 1995;50:1093-6. (3)

121. Nathwani D, Wood MJ. Penicillins. A current review of their clinical pharmacology and therapeutic use. Drugs 1993:45:866-94. (4).

122. Scaglione F, Raichi M, Fraschini F. Serum protein binding and extravascular diffusion of methoxyimino cephalosporins. Time courses of free and total concentrations of cefotaxime and ceftriaxone in serum and pleural exudate. $J$ Antimicrob Chemother 1990;26(Suppl A):1-10. (2+).

123. Taryle DA, Good JT Jr, Morgan EJ III, et al. Antibiotic concentrations in human parapneumonic effusions. J Antimicrob Chemother 1981;7:171-7. (2+).

124. Teixeira LR, Villarino MA. Antibiotic treatment of patients with pneumonia and pleural effusion. Curr Opin Pulm Med 1998:4:230-4. (4).

125. Shohet I, Yellin A, Meyerovitch J, et al. Pharmacokinetics and therapeutic efficacy of gentamicin in an experimental pleural empyema rabbit model. Antimicrob Agents Chemother 1987;31:982-5. (2+).

126. Teixeira LR, Sasse SA, Villarino MA, et al. Antibiotic levels in empyemic pleural fluid. Chest 2000;117:1734-9. (4).

127. Thys JP, Serruys-Schoutens E, Rocmans P, et al. Amikacin concentrations in uninfected postthoracotomy pleural fluid and in serum after intravenous and intrapleural injection. Chest 1984:85:502-5. (3)

128. Thys JP, Vanderhoeft P, Herchuelz A, et al. Penetration of aminoglycosides in uninfected pleural exudates and in pleural empyemas. Chest 1988;93:530-2. (3)

129. Huchon G, Woodhead M. Guidelines for management of adult community-acquired lower respiratory tract infections. European Study on Community Acquired Pneumonia (ESOCAP) Committee. Eur Respir J 1998;11:986-91. (4).

130. Hammond JM, Potgieter PD, Hanslo D, et al. The etiology and antimicrobia susceptibility patterns of microorganisms in acute community-acquired lung abscess. Chest 1995;108:937-41. (3).

131. Shinzato T, Saito A. A mechanism of pathogenicity of "Streptococcus milleri group" in pulmonary infection: synergy with an anaerobe. J Med Microbio 1994:40:118-23. (2+)

132. Shinzato T, Saito A. The Streptococcus milleri group as a cause of pulmonary infections. Clin Infect Dis 1995;21(Suppl 3):S238-43. (3). 
133. Liapakis IE, Kottakis I, Tzatzarakis MN, et al. Penetration of newer quinolones in the empyema fluid. Eur Respir J 2004;24:466-70. (2+).

134. Liapakis IE, Light RW, Pitiakoudis MS, et al. Penetration of clarithromycin in experimental pleural empyema model fluid. Respiration 2005;72:296-300. (2+).

135. Sahn SA. Management of complicated parapneumonic effusions. Am Rev Respir Dis 1993:148:813-17. (4).

136. Finegold SM, Wexler HM. Present studies of therapy for anaerobic infections. Clin Infect Dis 1996;23(Suppl 1):S9-14. (4)

137. Kroboth FJ, Yu VL, Reddy SC et al. Clinicoradiographic correlation with the extent of Legionnaire disease. AJR Am J Roentgenol 1983;141:263-8. (2+).

138. Randolph KA, Beekman JF. Legionnaires' disease presenting with empyema. Chest 1979:75:404-6. (3).

139. Fine NL, Smith LR, Sheedy PF. Frequency of pleural effusions in mycoplasma and viral pneumonias. N Engl J Med 1970;283:790-3. (3).

140. Mansel JK, Rosenow EC III, Smith TF, et al. Mycoplasma pneumoniae pneumonia. Chest 1989;95:639-46. (3).

141. Department of Health. Screening for meticillin-resistant Staphylococcus aureus (MRSA) colonisation. A strategy for NHS Trusts: a summary of best practice. http:// www.dh.gov.uk/reducingmrsa (accessed 2006). (4)

142. Kollef MH, Shorr A, Tabak YP, et al. Epidemiology and outcomes of health-careassociated pneumonia: results from a large US database of culture-positive pneumonia. Chest 2005;128:3854-62. (2+).

143. Maclayton DO, Hall RG. Pharmacologic treatment options for nosocomial pneumonia involving methicillin-resistant Staphylococcus aureus. Ann Pharmacother 2007; 41:235-44. $(2++)$

144. Naimi TS, LeDell KH, Como-Sabetti K, et al. Comparison of community- and health care-associated methicillin-resistant Staphylococcus aureus infection. JAMA 2003:290:2976-84. (2+)

145. Aye RW, Froese DP, Hill LD. Use of purified streptokinase in empyema and hemothorax. Am J Surg 1991;161:560-2. (3)

146. Bergh NP, Ekroth R, Larsson S, et al. Intrapleural streptokinase in the treatment of haemothorax and empyema. Scand J Thorac Cardiovasc Surg 1977; 11:265-8. (3)

147. Berglin E, Ekroth R, Teger-Nilsson AC, et al. Intrapleural instillation of streptokinase. Effects on systemic fibrinolysis. Thorac Cardiovasc Surg 1981;29:124-6. (3).

148. Bouros D, Schiza S, Panagou P, et al. Role of streptokinase in the treatment of acute loculated parapneumonic pleural effusions and empyema. Thorax 1994:49:852-5. (3).

149. Chin NK, Lim TK. Controlled trial of intrapleural streptokinase in the treatment of pleural empyema and complicated parapneumonic effusions. Chest 1997:111:275-9. (2-)

150. Cohen ML, Finch IJ. Transcatheter intrapleural urokinase for loculated pleural effusion. Chest 1994;105:1874-6. (3)

151. Davies CW, Lok S, Davies RJ. The systemic fibrinolytic activity of intrapleural streptokinase. Am J Respir Crit Care Med 1998;157:328-30. (2+)

152. Fraedrich G, Hofmann D, Effenhauser $P$, et al. Instillation of fibrinolytic enzymes in the treatment of pleural empyema. Thorac Cardiovasc Surg 1982;30:36-8. (3)

153. Godley PJ, Bell RC. Major hemorrhage following administration of intrapleural streptokinase. Chest 1984;86:486-7. (3).

154. Henke CA, Leatherman JW. Intrapleurally administered streptokinase in the treatment of acute loculated nonpurulent parapneumonic effusions. Am Rev Respir Dis 1992;145:680-4. (3)

155. Jerjes-Sanchez C, Ramirez-Rivera A, Elizalde JJ, et al. Intrapleural fibrinolysis with streptokinase as an adjunctive treatment in hemothorax and empyema: a multicenter trial. Chest 1996;109:1514-19. (3)

156. Laisaar T, Puttsepp E, Laisaar V. Early administration of intrapleural streptokinase in the treatment of multiloculated pleural effusions and pleural empyemas. Thorac Cardiovasc Surg 1996;44:252-6. (3)

157. Mitchell ME, Alberts WM, Chandler KW, et al. Intrapleural streptokinase in management of parapneumonic effusions. Report of series and review of literature. J Fla Med Assoc 1989;76:1019-22. (3).

158. Moulton JS, Moore PT, Mencini RA. Treatment of loculated pleural effusions with transcatheter intracavitary urokinase. AJR Am J Roentgenol 1989;153:941-5. (3)

159. Moulton JS, Benkert RE, Weisiger KH, et al. Treatment of complicated pleural fluid collections with image-guided drainage and intracavitary urokinase. Chest 1995:108:1252-9. (3).

160. Ogirala RG, Williams MH Jr. Streptokinase in a loculated pleural effusion Effectiveness determined by site of instillation. Chest 1988;94:884-6. (3)

161. Park CS, Chung WM, Lim MK, et al. Transcatheter instillation of urokinase into loculated pleural effusion: analysis of treatment effect. AJR Am J Roentgenol 1996;167:649-52. (3).

162. Pollak JS, Passik CS. Intrapleural urokinase in the treatment of loculated pleura effusions. Chest 1994;105:868-73. (3)

163. Porter J, Banning AP. Intrapleural streptokinase. Thorax 1998:53:720. (3)

164. Robinson LA, Moulton AL, Fleming WH, et al. Intrapleural fibrinolytic treatment of multiloculated thoracic empyemas. Ann Thorac Surg 1994;57:803-13. (3)

165. Roupie E, Bouabdallah K, Delclaux C et al. Intrapleural administration of streptokinase in complicated purulent pleural effusion: a CT-guided strategy. Intensive Care Med 1996;22:1351-3. (3)
166. Ryan JM, Boland GW, Lee MJ, et al. Intracavitary urokinase therapy as an adjunct to percutaneous drainage in a patient with a multiloculated empyema. AJR Am J Roentgenol 1996;167:643-7. (3)

167. Taylor RF, Rubens MB, Pearson MC, et al. Intrapleural streptokinase in the management of empyema. Thorax 1994;49:856-9. (3).

168. Temes RT, Follis F, Kessler RM, et al. Intrapleural fibrinolytics in management of empyema thoracis. Chest 1996;110:102-6. (3)

169. Willsie-Ediger SK, Salzman G, Reisz G, et al. Use of intrapleural streptokinase in the treatment of thoracic empyema. Am J Med Sci 1990:300:296-300. (3).

170. Bouros D, Schiza S, Patsourakis G, et al. Intrapleural streptokinase versus urokinase in the treatment of complicated parapneumonic effusions: a prospective, double-blind study. Am J Respir Crit Care Med 1997:155:291-5. (1+).

171. Bouros D, Schiza S, Tzanakis N, et al. Intrapleural urokinase versus normal saline in the treatment of complicated parapneumonic effusions and empyema. A randomized, double-blind study. Am J Respir Crit Care Med 1999;159:37-42. (1+).

172. Cameron R, Davies HR. Intra-pleural fibrinolytic therapy versus conservative management in the treatment of parapneumonic effusions and empyema. Cochrane Database Syst Rev 2004:CD002312. (1++).

173. Davies RJ, Traill ZC, Gleeson FV. Randomised controlled trial of intrapleural streptokinase in community acquired pleural infection. Thorax 1997;52:416-21. $(1+)$

174. Diacon AH, Theron J, Schuurmans MM, et al. Intrapleural streptokinase for empyema and complicated parapneumonic effusions. Am J Respir Crit Care Med 2004;170:49-53. $(1++)$.

175. Misthos P, Sepsas E, Konstantinou M, et al. Early use of intrapleural fibrinolytics in the management of postpneumonic empyema. A prospective study. Eur $\mathrm{J}$ Cardiothorac Surg 2005:28:599-603. (1-).

176. Talib SH, Verma GR, Arshad M, et al. Utility of intrapleural streptokinase in management of chronic empyemas. J Assoc Physicians India 2003:51:464-8. $(1+)$

177. Thomson AH, Hull J, Kumar MR, et al. Randomised trial of intrapleural urokinase in the treatment of childhood empyema. Thorax 2002;57:343-7. (1+).

178. Tuncozgur B, Ustunsoy $\mathrm{H}$, Sivrikoz MC, et al. Intrapleural urokinase in the management of parapneumonic empyema: a randomised controlled trial. Int J Clin Pract 2001;55:658-60. $(\mathbf{1 + 1}$.

179. Bilaceroglu S, Cagerici U, Cakan A. Management of complicated parapneumonic effusions with image-guided drainage and intrapleural urokinase or streptokinase: a controlled randomized trial. Eur Respir J 1997:10:325S. (1 -).

180. Strange C, Allen ML, Harley R, et al. Intrapleural streptokinase in experimental empyema. Am Rev Respir Dis 1993;147:962-6. (2+).

181. Alfageme I, Vazquez R. Ventricular fibrillation after intrapleural urokinase. Intensive Care Med 1997;23:352. (3)

182. Frye MD, Jarratt M, Sahn SA. Acute hypoxemic respiratory failure following intrapleural thrombolytic therapy for hemothorax. Chest 1994;105:1595-6. (3).

183. Light RW, Nguyen T, Mulligan ME, et al. The in vitro efficacy of varidase versus streptokinase or urokinase for liquefying thick purulent exudative material from loculated empyema. Lung 2000;178:13-18. (2+).

184. Simpson G, Roomes D, Heron M. Effects of streptokinase and deoxyribonuclease on viscosity of human surgical and empyema pus. Chest 2000:117:1728-33. (2+).

185. Frederiksen B, Pressler T, Hansen A, et al. Effect of aerosolized rhDNase (Pulmozyme) on pulmonary colonization in patients with cystic fibrosis. Acta Paediatr 2006:95:1070-4. (1+).

186. Parks QM, Young RL, Poch KR, et al. Neutrophil enhancement of Pseudomonas aeruginosa biofilm development: human F-actin and DNA as targets for therapy. J Med Microbiol 2009:58:492-502. (2+).

187. Whitchurch CB, Tolker-Nielsen T, Ragas PC, et al. Extracellular DNA required fo bacterial biofilm formation. Science 2002:295:1487. (2+).

188. Evans AL, Gleeson FV. Radiology in pleural disease: state of the art. Respirology 2004:9:300-12. (4)

189. Millar AB, Boothroyd AE, Edwards D, et al. The role of computed tomography (CT) in the investigation of unexplained haemoptysis. Respir Med 1992:86:39-44. (3).

190. Naidich DP, Lee JJ, Garay SM, et al. Comparison of CT and fiberoptic bronchoscopy in the evaluation of bronchial disease. AJR Am J Roentgenol 1987;148:1-7. (3)

191. Naidich DP, Harkin TJ. Airways and lung: correlation of CT with fiberoptic bronchoscopy. Radiology 1995;197:1-12. (4)

192. Qureshi NR, Gleeson FV. Imaging of pleural disease. Clin Chest Med 2006;27:193-213. (4)

193. Woodring JH. Determining the cause of pulmonary atelectasis: a comparison of plain radiography and CT. AJR Am J Roentgenol 1988;150:757-63. (3).

194. McLoud TC. CT and MR in pleural disease. Clin Chest Med 1998;19:261-76. (4)

195. Moulton AL. Surgical definition of pleural peel. Radiology 1991;178:889-90. (4)

196. Neff CC, vanSonnenberg E, Lawson DW, et al. CT follow-up of empyemas: pleural peels resolve after percutaneous catheter drainage. Radiology 1990;176:195-7. (3)

197. Kearney SE, Davies CW, Tattersall DJ, et al. The characteristics and significance of thoracic lymphadenopathy in parapneumonic effusion and empyema. $\mathrm{Br} \mathrm{J}$ Radiol 2000:73:583-7. (3)

198. Pothula V, Krellenstein DJ. Early aggressive surgical management of parapneumonic empyemas. Chest 1994;105:832-6. (3) 
199. Bilgin M, Akcali Y, Oguzkaya F. Benefits of early aggressive management of empyema thoracis. Aust NZ J Surg 2006; 76:120-2. (1-).

200. Jimenez CD, Diaz G, Perez-Rodriguez E, et al. Prognostic features of residual pleural thickening in parapneumonic pleural effusions. Eur Respir $\mathrm{J}$ 2003;21:952-5. $(\mathbf{2}+)$.

201. Martinez MA, Cordero PJ, Cases E, et al. Prognostic features of residual pleural thickening in metapneumonic pleural effusion. Arch Bronconeumol 1999;35:108-12. (2)

202. Amin R. Non-Hodgkin's lymphoma complicating chronic pyothorax. J R Soc Med 1999;92:89-90. (3)

203. Aozasa K, Takakuwa T, Nakatsuka S. Pyothorax-associated lymphoma: a lymphoma developing in chronic inflammation. Adv Anat Pathol 2005:12:324-31. (4).

204. Aozasa K. Pyothorax-associated lymphoma. J Clin Exp Hematol 2006; 46:5-10. (3).

205. Iuchi K, Aozasa K, Yamamoto S, et al. Non-Hodgkin's lymphoma of the pleural cavity developing from long-standing pyothorax. Summary of clinical and pathological findings in thirty-seven cases. Jpn J Clin Oncol 1989;19:249-57. (3).
206. Iuchi K, Ohsawa M, Tomita Y, et al. Angiomatous lesions in the wall of chronic pyothorax. Mod Pathol 1995;8:417-20. (3).

207. Kanno H, Aozasa K. Mechanism for the development of pyothorax-associated lymphoma. Pathol Int 1998;48:653-64. (4).

208. Nakatsuka S, Nishiu M, Tomita Y, et al. Enhanced expression of neuron-specific enolase (NSE) in pyothorax-associated lymphoma (PAL) Jpn J Cancer Res 2002;93:411-16. (3).

209. Narimatsu H, Ota Y, Kami M, et al. Clinicopathological features of pyothoraxassociated lymphoma; a retrospective survey involving 98 patients. Ann Oncol 2007:18:122-8. (3)

210. O'Donovan M, Silva I, Uhlmann V, et al. Expression profile of human herpesvirus 8 (HHV-8) in pyothorax associated lymphoma and in effusion lymphoma. Mol Pathol 2001;54:80-5. (3)

211. Sasajima Y, Yamabe H, Kobashi Y, et al. High expression of the Epstein-Barr virus latent protein EB nuclear antigen-2 on pyothorax-associated lymphomas. Am J Pathol 1993;143:1280-5. (2-).

212. Johnson PH, Macfarlane JT. Commentary: pleural empyema and malignancy-another dimension. Thorax 1996;51:107-8. (4). 